\title{
Antithrombotic treatment in stable coronary syndromes: long-term intermittent urokinase therapy in end-stage coronary artery disease and refractory angina pectoris
}

\author{
Frank-Chris Schoebel, Thomas W Jax, Yuriko Fischer, Bodo-Eckehard Strauer, \\ Matthias Leschke
}

\begin{abstract}
Interventions that modify lipid metabolism and blood coagulation have been shown to favourably influence the natural course of coronary artery disease in terms of the primary prevention and treatment of acute cardiovascular events. Various findings suggest that such interventions may also preserve and enhance myocardial perfusion in the chronic stage of the disease. Long-term intermittent urokinase therapy was developed for patients with end-stage coronary artery disease and refractory angina pectoris. $A$ dose of 500000 IU of urokinase given intravenously as a bolus three times a week for of 12 weeks reduced symptoms by $70 \%$ and was accompanied by objective improvements in myocardial perfusion and an increase of ergometric exercise capacity. The possible therapeutic mechanisms of long-term intermittent urokinase therapy-improvement of rheological blood properties mediated by fibrinogen reduction, thrombolysis of non-occlusive subclinical thrombi, and regression of atherosclerotic plaques-are discussed in the context of other antithrombotic approaches.
\end{abstract}

(Heart 1997;77:13-17)

Medizinische Klinik und Poliklinik B, Klinik für Kardiologie, Pneumologie und Angiologie, HeinrichHeine Universität Düsseldorf, Düsseldorf, Germany F-C Schoebel T W Jax

Y Fischer

B E Strauer

$M$ Leschke

Correspondence to: Dr F-C Schoebel Medizinische Klinik und Poliklinik B, Klinik für Kardiologie, Pneumologie und Angiologie, HeinrichHeine Universität Düsseldorf, Moorenstraße 5 40225 Düsseldorf, Germany.

Accepted for publication 12 June 1996 ductance vessels, a reduction in heart rate, in some cases direct modification of the cellular metabolism of the myocytes. ${ }^{1}$ Even though such approaches reduce myocardial ischaemia and hence increase the quality of life in patients with angina pectoris they only marginally influence the pathogenesis of coronary atherosclerosis.

Like reducing LDL-cholesterol, which has been shown to reduce major cardiovascular events and morphological disease progression ${ }^{2}$ and improve LDL-cholesterol dependent disturbances of coronary vasomotion,,$^{3-7}$ use of antithrombotic substances is another approach to favourably influence the pathogenesis of the underlying disease process and hence reduce chronic myocardial ischaemia. Substances from all three major classesantiplatelet agents, anticoagulants, thrombolytics-have a beneficial effect on the clinical course of the acute coronary syndromes, especially in acute myocardial infarction, which is dominated by occlusive coronary thrombus formation. Aspirin has also been shown to be of benefit in the primary and secondary prevention of acute coronary syndromes in clinically stable patients. ${ }^{8}$ In addition to its importance in the acute coronary syndromes, coronary thrombosis is of relevance to morphological disease progression in clinically stable patients, because plaque rupture may lead to an asymptomatic, non-occlusive thrombus, which in the event of incomplete endogenous lysis is incorporated by the arterial wall as solidified plaque material. ${ }^{910}$ It is therefore likely that long term treatment with antithrombotic substances may slow the progression of morphological disease or even cause regression of vascular obstructions with subsequent preservation or enhancement of coronary blood flow. One therapeutic approach which is aimed at these mechanisms is long-term intermittent urokinase therapy, a low-dose thrombolytic regimen for the treatment of patients with end-stage coronary artery disease and refractory angina pectoris.

\section{Long-term intermittent urokinase} therapy APPLICATION

Long-term intermittent urokinase therapy was developed for patients with refractory angina pectoris, defined as a persistence of angina pec- 
Table 1 Comparison of the effects on rheological variables and clinical symptoms ${ }^{14}$ of $50000 \mathrm{IU}$ and $500000 \mathrm{IU}$ urokinase per injection given three times a week over 12 weeks

\begin{tabular}{|c|c|c|c|c|c|}
\hline & \multicolumn{2}{|c|}{$3 \times 50000$ IU/week $(n=43)$} & \multicolumn{2}{|c|}{$3 \times 500000$ IUlweek $(n=46)$} & \multirow[b]{2}{*}{ P value } \\
\hline & $\begin{array}{l}\text { Before } \\
\text { (mean (SD)) }\end{array}$ & $\begin{array}{l}\text { After } \\
\text { (mean (SD)) }\end{array}$ & $\begin{array}{l}\text { Before } \\
\text { (mean (SD)) }\end{array}$ & $\begin{array}{l}\text { After } \\
\text { (mean (SD)) }\end{array}$ & \\
\hline $\begin{array}{l}\text { Rheological variables: } \\
\text { Fibrinogen }(\mathrm{mg} / \mathrm{dl}) \\
\text { Plasma viscosity }\left(\mathrm{mPa} \cdot \mathrm{s}^{-1}\right) \\
\text { Red blood cell aggregation (U) }\end{array}$ & $\begin{array}{c}351(79) \\
1.38(0.09) \\
15.0(3.0)\end{array}$ & $\begin{array}{c}333(63) \\
1.37(0.09) \\
14.0(3.2)\end{array}$ & $\begin{array}{c}369(66) \\
1.40(0 \cdot 05) \\
14 \cdot 8(2 \cdot 7)\end{array}$ & $\begin{array}{l}242(40) \\
1.31(0 \cdot 05) \\
11 \cdot 7(2 \cdot 3)\end{array}$ & $\begin{array}{r}<0.001 \\
<0.001 \\
0.001\end{array}$ \\
\hline $\begin{array}{l}\text { Clinical variables: } \\
\text { Angina pectoris (events/wk) } \\
\text { Intake of nitrate capsules } \\
\text { (capsules/wk) } \\
\text { Responders (reduction of } \\
\text { angina pectoris }>66 \% \text { ) (\%) } \\
\text { Patients free symptoms (\%) }\end{array}$ & $\begin{array}{l}21 \cdot 9(9 \cdot 8) \\
13 \cdot 1(7 \cdot 9)\end{array}$ & $\begin{array}{l}15 \cdot 8(10 \cdot 0) \\
8 \cdot 9(6 \cdot 1) \\
21 \\
7\end{array}$ & $\begin{array}{l}24 \cdot 2(11 \cdot 7) \\
14 \cdot 1(11 \cdot 1)\end{array}$ & $\begin{array}{l}7 \cdot 1(7 \cdot 1) \\
2 \cdot 3(3 \cdot 4) \\
70 \\
17\end{array}$ & $\begin{array}{r}<0.001 \\
<0.001 \\
<0.001 \\
0.005\end{array}$ \\
\hline
\end{tabular}

toris class 3 and 4 (defined according to the criteria of the Canadian Cardiovascular Society ${ }^{11}$ ) despite maximally tolerated conventional medical treatment (nitrates, $\beta$ blockers, calcium antagonists). To avoid withholding an established form of treatment, an experienced team of cardiologists and cardiac surgeons must, on the basis of a recent coronary angiogram, rule out the use of conventional invasive revascularisation procedures such as coronary artery bypass grafting (CABG) or percutaneous transluminal coronary angioplasty (PTCA).

Long-term intermittent urokinase therapy is clinically effective at a dose of 500000 IU given as an intravenous bolus injection three times a week for 12 weeks in patients whose fibrinogen concentrations are more than $300 \mathrm{mg} / \mathrm{dl}$ at baseline. ${ }^{12-14}$ Treatment may be initiated in hospital or begun as an outpatient regimen immediately with target fibrinogen concentrations of 200-250 mg/dl. Clinical symptoms, fibrinogen concentrations, and activated partial thromboplastin time are monitored every two weeks.

Several studies in patients with refractory angina pectoris showed a reduction in the frequency of spontaneous angina pectoris accompanied by an increase in exercise capacity and an enhancement of scintigraphically and electrocardiographically measured myocardial perfusion. ${ }^{12-14}$ The improvement in clinical symptoms lasted at least three months after the end of therapy. ${ }^{13} \mathrm{~A}$ randomised dose-response study further validated this therapeutic approach $^{14}$ : it compared a rheologically effective weekly dosage of $3 \times 500000$ IU with a weekly dosage of $3 \times 50000 \mathrm{IU}$ and found that the therapeutic effects were significantly dosedependent (table 1). Side effects such as an increased rate of cardiovascular ischaemic events and gastrointestinal bleeding complications were not seen (table 2)..$^{14}$

\section{MECHANISMS OF ANTI-ISCHAEMIC}

EFFECTIVENESS

Improvement of rheological blood properties

Long-term intermittent urokinase therapy was

Table 2 Comparison of side effects ${ }^{14}$ when 50000 IU and 500000 IU urokinase per injection were given three times a week over 12 weeks

\begin{tabular}{lll}
\hline Side effects & $\begin{array}{l}3 \times 50000 I U / w k \\
(n=49)\end{array}$ & $\begin{array}{l}3 \times 500000 I U / w k \\
(n=49)\end{array}$ \\
\hline Unstable angina pectoris & 3 & 1 \\
Myocardial infarction & 2 & 1 \\
Upper gastrointestinal tract bleeding & 0 & 1 \\
Dropped out for no specific reason & 1 & 0 \\
\hline
\end{tabular}

originally developed under the assumption that an improvement in rheological blood properties-for example, the reduction of fibrinogen mediated by the fibrinogenolytic action of urokinase-may enhance blood flow at the microcirculatory level. ${ }^{12}{ }^{16}$ Pathological alterations of rheological blood properties, including large increases in fibrinogen concentrations and increases in plasma viscosity and red blood cell aggregation are characteristic features of patients with refractory angina pectoris. ${ }^{14}$ These rheological variables are higher in patients with refractory angina not only when compared with values in subjects who have no angiographic evidence of atherosclerotic disease but also compared with patients who have coronary artery disease and nonrefractory angina pectoris (fig 1).14 17

Blood viscosity is mainly determined by plasma viscosity, red blood cell aggregation, red blood cell deformability, and haematocrit. In non-obstructed coronary arteries, the flowlimiting resistance caused by blood viscosity can be ignored. ${ }^{18-20}$ However, in the poststenotic microcirculation when there have been severe and successive multiple stenoses, in occluded vessels, and in collateral vessels, ${ }^{21}$ blood viscosity (especially plasma viscosity and red blood cell aggregation) may limit blood flow and is therefore critical for oxygen delivery to the ischaemic myocardium. ${ }^{22}$ At the extremely low shear rates and almost zero flow in this area ${ }^{23}$ macromolecules, particularly fibrinogen, increase red blood cell aggregation and plasma viscosity; these in turn lead to an exponential increase in blood viscosity. ${ }^{181924}$ High linear correlations between fibrinogen and plasma viscosity as well as between fibrinogen and red blood cell aggregation have been demonstrated. ${ }^{14}$

Long-term intermittent urokinase therapy improves blood rheology in a dose-dependent manner (table 1). In a rheologically effective dose of 500000 IU per injection fibrinogen is reduced by about $33 \%$, while plasma viscosity and red blood cell aggregation are decreased by $6.4 \%$ and $19.9 \%$ respectively. ${ }^{14}$ Significant changes from baseline measurements are usually achieved after two to four weeks of treatment paralleled by clinical improvement and this effect levels off between the 6 th and 8 th week of treatment (fig 2). Reductions in fibrinogen are therefore higher than those of about $10-30 \%$ achieved with fibrate therapy ${ }^{25}$ and those of $19-24 \%$ achieved when long- 


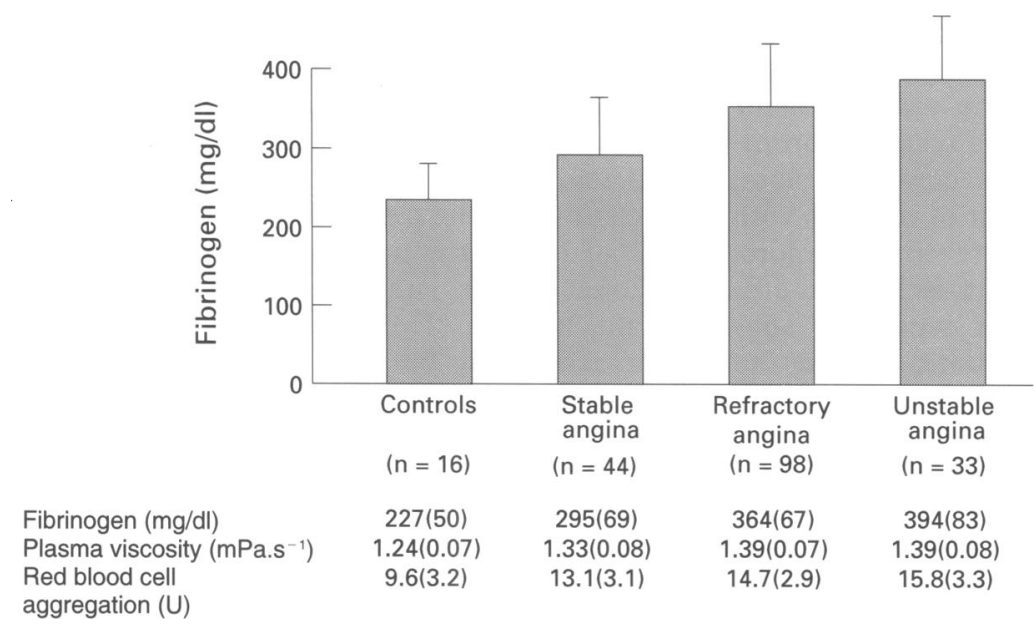

Figure 1 Fibrinogen and rheolgical variables in patients with stable, refractory, and unstable angina pectoris. ${ }^{14}$

Figure 2 Time course of fibrinogen $(A)$ and clinical symptoms (B) during treatment with long-term intermittent urokinase therapy at a dose of $50000 \mathrm{IU}(n=43$; open circles) or $500000 \mathrm{IU}$ urokinase per injection $(n=46 ;$ closed circles $) .{ }^{14}$ terolemia refractory to conventional lipid term low molecular weight heparin treatment or extracorporal LDL-cholesterol precipitation (HELP) was used. ${ }^{26}$ HELP treatment in the secondary prevention of coronary artery disease in patients with familial hypercholeslowering therapy reduces angina in patients with stable coronary artery disease; this effect is in part attributed to a marked improvement in rheological blood properties. ${ }^{27}$

\section{Thrombolytic potential}

In a postmortem study plaque fissures or thrombi were found in $22 \%$ of the patients with atheroma related diseases who were clinically stable and had died of non-cardiac
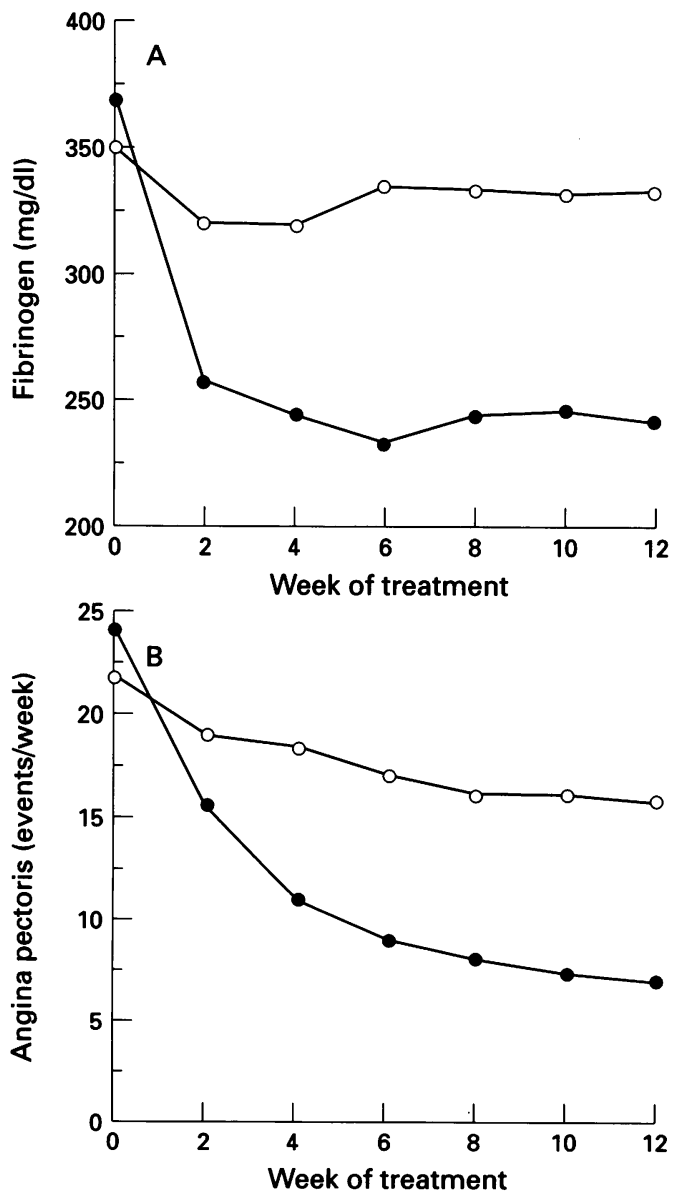

causes. ${ }^{28}$ This figure has recently been confirmed by an angiographic study in patients with stable coronary artery disease who underwent coronary angioplasty. Angiography showed coronary thrombus at the site of the target stenosis in $19 \%$ of the cases before intervention. ${ }^{29}$ Thrombi therefore may limit flow in the epicardial conductance vessels ${ }^{10}$ and in the coronary microcirculation ${ }^{3031}$ not only in the acute coronary syndromes but also in clinically stable coronary artery disease. In patients with refractory angina pectoris in endstage coronary artery disease, multiple, severe, and often successive coronary stenoses lead to regions of poststenotic recirculation and relative stasis of blood flow. The reduction in blood fluidity resulting from increases in plasma viscosity and red blood cell aggregation and the fluid-dynamic aspects of coronary stenoses favours intracoronary thrombus formation. ${ }^{32}$

Fibrinogen has been positively related to major thrombotic cardiovascular events, ${ }^{33}$ which is explained by its impact on blood rheology and its contribution as the major linkage molecule in platelet aggregation ${ }^{34}$ and therefore it must per se be regarded as a major promotor of intracoronary thrombus formation. ${ }^{9}{ }^{1035}$ These aspects are further substantiated by positive interrelations between fibrinogen and thrombin generation ${ }^{36}$ and by increases in plasmin- $a$-antiplasmin ${ }^{37}$ and $\mathrm{D}$ dimers $^{36}$ which are indicators of increased, probably secondary, endogenous thrombolytic activity in patients with raised fibrinogen concentrations. Therefore increases in fibrinogen indicate a procoagulant disease state in patients with coronary artery disease.

These aspects of thrombogenic (and therefore dynamic) impairment of blood flow indicate that the thrombolytic efficacy of long-term intermittent urokinase therapy is a major factor in improving myocardial perfusion in patients with refractory angina pectoris and raised concentrations of fibrinogen. Different therapeutic regimens of low-dose urokinase have thrombolytic potential ${ }^{12} 3839$ and indirect evidence of pharmacodynamic effectiveness is indicated by a reduction of about $8 \%$ in the activity of plasminogen, which is the substrate of urokinase, in patients with refractory angina pectoris after the longterm intermittent administration of 500000 $\mathrm{IU}$ of urokinase (fig 3 ). ${ }^{12}$

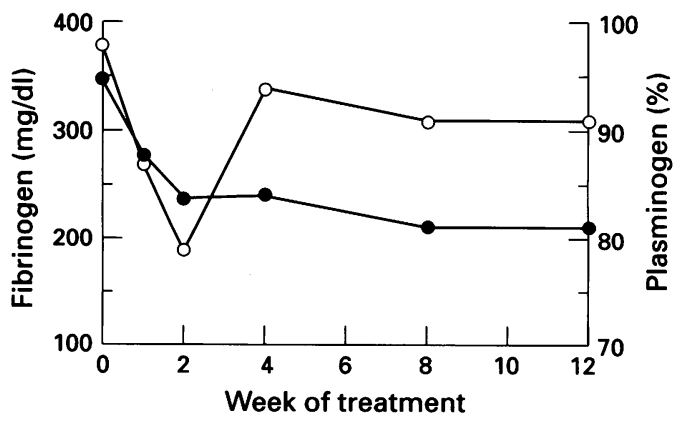

Figure 3 Significant decrease of fibrinogen (closed circles, $P<0.001$ ) and plasminogen (open circles, $P<0.05$ ) during treatment with 500000 IU per injection $(n=$ 
It has been pointed out previously that the prolonged administration of other antithrombotic substances, namely the anticoagulants heparin and warfarin reduces residual thrombus and therefore enhances coronary blood flow after the acute treatment of patients with acute coronary syndromes. ${ }^{4041}$ Furthermore, two recent studies of the anti-ischaemic efficacy of low molecular weight heparin ${ }^{42}{ }^{43}$ support the use of antithrombotic therapy to improve myocardial perfusion in clinically stable patients. As well as the induction of collateral angiogenesis and functional improvement of collaterals suggested by one group ${ }^{43}$ the antithrombotic efficacy of low molecular weight heparin ${ }^{36}{ }^{42}$ was particularly useful in patients with high fibrinogen concentrations. Interestingly one study showed a $15 \%$ reduction in fibrinogen after low-molecular weight heparin was given for three months. ${ }^{42}$

\section{Plaque regression}

Fibrinogen and fibrin are major constituents of atherosclerotic plaques, ${ }^{44-46}$ and high concentrations of fibrinogen are positively correlated with the extent of atheroma in the coronary and carotid arteries. ${ }^{47} 48$ This correlation is probably the result of repetitive plaque fissuring and the secondary formation of coronary thrombus, which because of incomplete endogenous lysis becomes incorporated into the plaque. Subsequently there is rapid, nonlinear morphological plaque progression..$^{910}$ In addition, high plasma concentrations of fibrinogen increase the fibrin content of the plaque by direct permeation. ${ }^{44} 49$

It is therefore probable that long-term thrombolytic therapy can lead to morphological plaque regression, which is important for blood flow in critically stenosed arteries. This effect of thrombolytic therapy on plaque regression may explain the persistence of clinical long-term results of a weekly dose of $3 \times$ 500000 IU urokinase beyond the treatment period. ${ }^{13} 15$

In this context it is noteworthy that the administration of another antithrombotic regimen, high dose aspirin $(975 \mathrm{mg} / \mathrm{d})$ in combination with dipyridamole $(225 \mathrm{mg} / \mathrm{d})$, even though it did not retard angiographic progression of pre-existing coronary lesions, reduced the formation of new lesions compared with placebo $(23 \% \quad v \quad 35 \%)$ over a five year period)..$^{50}$ Investigations of disease progression in coronary and carotid atherosclerosis indicated that the effects on morphological progression may be dose-dependent. ${ }^{51} 52$ Even though major effects on the morphological regression of coronary artery disease during heparin-induced extracorporal LDL-cholesterol apheresis and bezafibrate relate to reductions in lipids they may be partially mediated by the decrease of fibrinogen which in a practical sense makes these interventions "antithrombotic". ${ }^{27} 53$

\section{Conclusion}

Based on the current concepts of the pathogenesis of coronary atherosclerosis, antithrom- botic agents offer ways to favourably influence morphological disease progression as well as functional aspects of coronary blood flow. These effects are mainly but not exclusively mediated by antithrombotic mechanisms as for example in the case of rheological effectiveness of long-term urokinase or the probable angioneogenetic impact of low-molecular weight heparin. Even though these various approaches may be limited in their practical usefulness in the general population of patients with coronary artery disease-for example, by dose or mode of applicationthey point to the clinical relevance of an important therapeutic principle, which may be addressed in more practical ways by future developments. In this context long-term intermittent urokinase therapy represents a therapeutically effective and safe approach to the treatment of patients with end-stage coronary artery disease and refractory angina pectoris.

We thank Sabine Meyer for the careful help in the preparation of the typescript.

1 Lichtlen PR. Pathophysiology of coronary and myocardial function in angina pectoris: important aspects for drug treatment. Eur Heart $\mathcal{F}$ 1985;6(suppl F):11-25.

2 Gotto AM. Lipid lowering, regression and coronary events - a review of the interdisciplinary council on lipids and cardiovascular risk intervention, seventh council and cardiovascular risk intervention,

3 Leung WH, Lau CP, Wong CK. Beneficial effect of cholesterol-lowering therapy on coronary endothelium-dependent relaxation in hypercholesterolaemic patients. Lance 1993;341:1496-1500.

4 Egashira K, Hirooka Y, Kai H, Sugimachi M, Suzuki S, Inou $T$, et al. Reduction in serum cholesterol with pravastatin improves endothelium-dependent coronary vasomotion in patients with hypercholesterolemia. Circulation 1994;89:2519-24.

5 Treasure CB, Klein Jl, Weintraub WS, Talley J, Stillablower ME, Kosinski AS, et al. Benefical effects of cholesterol-lowering therapy on the coronary endothelium in patients with coronary artery disease. $N$ Engl $\dot{f}$ Med 1995;332:481-7.

6 Anderson TJ, Meredith JT, Yeung AC, Frei B, Selwyn AP, Ganz P. The effect of cholesterol-lowering and antioxidant therapy on endothelium-dependent coronary vasomotion. N Engl f Med 1995;332:488-93.

7 Gould KL, Martucci JP, Goldberg DJ, Hess MJ, Edens $\mathrm{RP}$, Latifi $\mathrm{R}$, et al. Short-term cholesterol lowering decreases size and severity of perfusion abnormalities by positron emission tomography-a potential nononvasive marker of healing endothelium. Circulation 1994;89: $1530-8$.

8 Di Salvo TG, Fuster V. Antithrombotic therapy in coronary artery disease. Curr Opin Lipidol 1994;5:290-304.

9 Fuster V, Badimon L, Badimon J, Chesebro J. The pathogenesis of coronary artery disease and the acute coronary syndromes (1). N Engl f Med 1992;326:242-50.

10 Fuster V, Badimon L, Badimon J, Chesebro J. The pathogenesis of coronary artery disease and the acute coronary syndromes (2). N Engl F Med 1992;326:310-8.

11 Campeau L. Grading of angina pectoris. Circulation 1976;54:522-3

12 Leschke M, Höffken H, Motz W, Blanke H, Schoebel FC Strauer BE. Chronisch-intermittierende Urokinasetherapie bei therapierefraktärer Angina pectoris. Dtsch Med Wschr 1992;117:81-7.

13 Schoebel FC, Leschke M, Jax TW, Stein D, Strauer BE Chronic-intermittent urokinase therapy in patients with end-stage coronary artery disease and refractory angina pectoris: a pilot study. Clin Cardiol 1996;19:115-20.

14 Leschke M, Schoebel FC, Mecklenbeck W, Stein D, Jax TW, Strauer BE. Long-term intermittent urokinase therapy in end-stage coronary artery disease and refractory angina pectoris: a randomized dose-response trial. $\mathcal{F} A m$ Coll Cardiol 1996;27:575-84.

15 Schoebel FC, Leschke M, Stein D, Heins M, Pels K, Jax TW, Strauer BE. Chronic-intermittent urokinase therapy in refractory angina pectoris. Fibrinolysis 1995;9(suppl. 1):121-5.

16 Ehrly AM, Schenk FJ. Systemisch niedrig dosierte Langzeit-Urokinasetherapie bei schwerster Angina pectoris. Grundlagen und erste Ergebnisse. In: Strauer BE Ehrly AM, Leschke M, eds. Fortschritte in der kardiovaskulären Rheologie. Munich: Münchner Wissenschaftliche Publikationen, 1987;35-8.

17 Leschke M, Blanke H, Stellwaag M, Motz W, Strauer BE. Hyperfibrinogenämie und pathologische Plasmaviskosität. Dtsch Med Wschr 1988;113:1 175-81. 
18 Schmid-Schönbein $\mathrm{H}$. Interaction of vasomotion and blood rheology in hemodynamics. In: Lowe GDO, Barbend JC, Forbes CD, eds. Clinical aspects of blood viscosity and cell deformability. Berlin: Springer, 1981;49-65.

19 Chien S. Physiological and pathophysiological significance of hemorheology. In: Chien S, Dormandy J, Ernst E, of hemorheology. In: Chien S, Dormandy J, Ernst E, Martinus Nijhoff, 1987:125-60.

20 Milnor WR. Hemodynamics. 2nd ed. Baltimore: Williams and Wilkins, 1989;11-20.

21 Wolf R, Lichtlen PR. Die Beziehung zwischen Plasmafibrinogen und der Funktion koronarer Kollateralgefäße. $Z$ Kardiol 1995;84:348-59.

22 Gordon RJ, Snyder GK, Tritel H, Taylor WJ. Potential significance of plasma viscosity and hematocrit variations in myocardial ischemia. Am Heart 7 1974;87:175-82.

23 Jan KM, Chien S, Bigger JT. Observations on blood viscosity changes after acute myocardial infarction. Circulation ity changes after acur.

24 Mattrai A, Whittington RB, Skalak R. Biophysics in clinical hemorheology. In: Chien S, Dormandy J, Ernst E, Mattrai A, eds. Clinical hemorheology. Dordrecht: Martinus Nijhoff, 1987;9-65.

25 Leschke M, Strauer BE. Fibrat Therapie. Münch Med Wschr 1992;46:744-8.

26 Seidel D, Armstrong VW, Schuff-Werner P for the HELP Study Group. The HELP-LDL-apheresis multicenter study, an angiographically assessed trial on the role of LDL-apharesis in the secondary prevention of coronary LDL-apharesis in the secondary prevention of coronary
heart disease. I. Evaluation of safety and cholesterol-lowering effects during the first 12 months. Eur 7 Clin Invest ering effects during

27 Schuff-Werner P, Gohlke H, Bartmann U, Baggio G, Corti MC, Dinsenbacher A, et al and the HELP Study Group. The HELP-LDL-apheresis multicenter study, an angiographically assessed trial on the role of LDL-apheresis in the secondary prevention of coronary heart disease. II Final evaluation of the effect of regular treatment on LDL-cholesterol plasma concentrations and the course of coronary heart disease. Eur 7 Clin Invest 1994;24: 724-32.

28 Davies MJ, Thomas AC, Knapman PA, Hangartner JR. Intramyocardial platelet aggregation in patients with unstable angina suffering sudden ischemic cardiac death. Circulation 1986;73:418-27.

29 Itoh A, Miyazaki S, Nonogi H, Daikoku S, Haze K. Angioscopic prediction of successful dilation and of restenosis in percutaneous transluminal coronary angioplasty-significance of the yellow plaque. Circulation 1995;91:1389-96.

30 Falk E. Unstable angina with fatal outcome: dynamic coronary thrombosis leading to infarction and/or sudden death: autopsy evidence of recurrent mural thrombosis with peripheral embolization culminating in vascular occlusion. Circulation 1985;71:699-708.

31 Davies MJ, Bland JM, Hangartner JRW, Angelini A, Thomas AC. Factors influencing the presence or absence of a acute coronary syndromes in sudden ischemic death. of a acute coronary syndrom

32 Koenig W, Ernst E. The possible role of hemorheology in atherothrombogenesis. Atherosclerosis 1992;94:93-107.

33 Ernst E, Resch L. Fibrinogen as a cardiovascular risk factor: a meta-analysis and review of the literature. $A n n$ Intern Med 1993;118:956-63.

34 Lefkovits J, Plow EF, Topol EJ. Platelet glycoprotein $\mathrm{IIb} / \mathrm{III}$ receptors in cardiovascular disease. $\mathrm{N} \mathrm{Engl} \mathcal{F} \mathrm{Med}$ 1995;332:1533-59.

35 Thompson SG, Kienast J, Pyke SDM, Haverkate F, van de Loo JCW for the European concerted Action on Thrombosis And Disabilities Angina Pectoris Study Group. Hemostatic factors and the risk of myocardial infarction or sudden death in patients with angina pectoris. $N$ Engl f Med 1995;332:635-41.
36 Ceriello A, Pirisi M, Giacomello R, Stel G, Falleti E, Motz $\mathrm{E}$, et al. Fibrinogen plasma levels as a marker of thrombin activation: new insights on the role of fibrinogen as a cardiovascular risk factor. Thromb Haemostas 1994;71: diovascula 5 .

37 Stein D, Schoebel FC, Heins M, Withold W, Pels K, Jax T, et al. Activation of the fibrinolytic system in patients with hyperfibrinogenemia and coronary artery disease (abstract). Ann Haematol 1995;70(suppl. I):359.

38 Wenzel E, Miyashita C, Köhler M, Nienhaus K, Jäger $H$. Veränderung des Gerinnungs-und Fibrinolysesystem unter Urokinase-Therapie. In: Trübestein G, ed. Urokinase therapy. Stuttgart-New York: FK Schattauer Verlag, 1981:21-33.

39 Cernigliaro C, Sansa M, Campi A, Bongo AS, Carfora A, Rizotti M, et al. Thrombolytic efficacy of a single intravenous bolus of urokinase in AMI: a dose range clinical trial (abstract). Circulation 1994;90(suppl. 2):I-168.

40 Douglas JS, Lutz JF, Clements SD, Robinson PH, Roubin $\mathrm{GS}$, Lembo NJ, et al. Therapy of large intracoronary thrombi in candidates for percutaneous transluminal coronary angioplasty (abstract). $\mathscr{f} \mathrm{Am}$ Coll Cardiol 1988; 11:238A.

41 Nakagawa S, Hanada Y, Koiwaya Y, Tanaka K. Angiographic features in prolonged anticoagulation: role of ruptured atheromatous plaque and adherent thrombus in acute myocardial infarction in vivo. Circulation 1988 ; 78:1335-44.

42 Melandri G, Semprini F, Cervi V, Candiotti N, Palazzini $\mathrm{E}$, Branzi A, et al. Benefit of adding low molecular weight heparin to the conventional treatment of stable angina pectoris:a double-blind, randomized, placebo-controlled pectoris: a double-blind, randomized,
trial. Circulation 1993;88:2517-23.

43 Quyyumi AA, Diodati JG, Lakatos EE, Bonow RO Epstein SE. Angiogenic effects of low molecular weight heparin in patients with stable coronary artery disease: pilot study. F Am Coll Cardiol 1993;22:635-41.

44 Smith EB, Alexander KM, Massie IB. Insoluble fibrin in human aortic intima. Quantitative studies on the relationship between insoluble fibrinogen and low-density lipoprotein. Atherosclerosis 1976;23:19-25.

45 Bini A, Fenoglia JJ, Mesa-Tejada R, Kudryk B, Kaplan KI Identification and distribution of fibrinogen, fibrin and fibrin(ogen) degradation products in atherosclerosis: use fibrin(ogen) degradation products in atherosclerosis: use

46 Smith EB, Keen GA, Grant A, Stirk C. Fate of fibrinogen in human arterial intima. Arteriosclerosis 1990;10;263-75.

47 Schneidau A, Harrison MJG, Hurst C, Wilkers HC, Meade TW. Arterial disease risk factors and angiographic evidence of atheroma of the carotid artery. Stroke 1989 20:1466-71

48 Broadhurst P, Kelleher C, Hughes, Imeson JD, Raftery EB. Fibrinogen, factor VII clotting activity and coronary artery disease severity. Atherosclerosis 1990;85:169-73.

49 Gurewich V, Lipinski B, Hyde E. The effect of the fibrinogen concentration and the leukocyte count on intravascular fibrin deposition from soluble fibrin monomer complexes. Thromb Haemostas 1976;36:605-14.

50 Chesebro JH, Webster MWI, Smith HC, Frye RL, Holmes DR, Reeder GS, et al. Antiplatelet therapy in coronary disease progression: reduced infarction and new lesion formation (abstract). Circulation 1989;80(suppl. II):266.

51 Brown BG, Bolson EL, Pierce CD, Petersen RB, Wong M Dodge HT. Progression of native coronary atherosclerosis is not altered by aspirin plus dipyridamole (abstract) Circulation 1983;68(suppl III):398.

52 Ranke C, Hecker H, Creutzig A, Alexander K. Dosedependent effect of aspirin on carotid atherosclerosis. Circulation 1993;87:1873-9.

53 Ericsson CG, Hamsten A, Nilson J, Grip L, Svane B, de Faire U. Angiographic assessement of effects of bezafibrate on progression of coronary artery disease in young male postinfarction patients. Lancet 1996;347:849-53. 